\title{
Low caloric value of ethanol itself increases alveolar bone loss in ligature- induced periodontitis in male rats
}

\section{Daniela Martins de Souza(a) Rosilene Fernandes da Rocha(b)}

(a) PhD, Dentistry Course, Pindamonhangaba College (FAPI), Christian Life University Foundation, Pindamonhangaba, SP, Brazil.

(b) PhD, School of Dentistry, São Paulo State University (UNESP), São José dos Campos, SP, Brazil.

\section{Corresponding author:}

Daniela Martins de Souza

Rua Armando Sales de Oliveira, 274,

apto. 53, Centro

Taubaté - SP - Brazil

CEP: 12030-080

E-mail:danimart.voy@terra.com.br

\begin{abstract}
This study aimed at morphometrically evaluating the influence of variable caloric values of ethanol consumption on alveolar bone loss in periodontitis in male rats. Thirty-six male rats were randomized into four groups of nine rats each, as follows: Test group A (low) - rats were fed an ethanol-containing liquid diet (ethanol representing $22 \%$ of total caloric value); Control group A - rats were fed a pair-fed control diet (ethanol replaced by isocaloric amounts of carbohydrate); Test group B (high) - rats were fed an ethanol-containing liquid diet (ethanol representing $36 \%$ of total caloric value); Control group B - rats were fed a pair-fed control diet for Test B. Following anesthesia, cotton ligatures were placed around the cervix of the right upper second molar. At eight weeks, the maxillary bones were removed and alveolar bone loss was analyzed by measuring the distance between the cementoenamel junction and the alveolar bone crest at buccal and palatal sites of the upper second molar. The unligated groups showed no significant differences between the bone loss values observed for the low and high caloric values of ethanol $(p>0.05)$. In the ligated groups, the rats receiving low caloric values of ethanol showed significantly greater bone loss compared to the isocaloric rats $(p<0.05)$; however, the rats receiving high caloric values of ethanol showed no significant differences compared to the controls. Analysis of the results demonstrated that, in male rats, ethanol itself affected ligature-induced bone loss when representing a low value in the total caloric value.
\end{abstract}

Descriptors: Ethanol; Alveolar bone loss; Periodontitis. 


\section{Introduction}

Periodontitis involves the destruction of supporting structures of the teeth, including the alveolar bone. ${ }^{1}$ Periodontitis is an infectious disease with a limited number of specific bacteria as disease initiators and host factors, which are the major determinants of disease occurrence and severity. ${ }^{2}$

A large variety of host characteristics influence the progression of periodontitis, including behavioral, social, systemic and genetic factors and the health of the host teeth. ${ }^{3-5}$ Social and behavioral factors include cigarette smoking, socioeconomic status, nutritional status, psychological factors and excessive alcohol consumption. ${ }^{4}$ Research suggests that alcohol consumption is associated with increased severity of periodontitis and may be a risk indicator for periodontal disease. ${ }^{6,7}$

The use of rat models has been validated in the evaluation of periodontal pathogenesis ${ }^{8}$ and in the assessment of the influence of risk factors, such as nicotine ${ }^{9}$ alcohol ${ }^{10,11,12}$ and stress, ${ }^{13}$ on disease progression.

Most studies ${ }^{6,714-18}$ in humans reporting on the association between alcohol and periodontal disease showed that alcohol consumption has a negative effect on periodontal tissues. However, other studies in humans have shown no relationship ${ }^{19}$ or a limited relationship ${ }^{20}$ between periodontal disease and alcohol consumption.

Considering that further studies are required to test the effect of ethanol consumption on periodontitis development, this study aimed at morphometrically evaluating the influence of variable caloric values of ethanol consumption on alveolar bone loss associated with ligature-induced periodontitis in male rats.

\section{Material and Methods Animals}

The Institutional Animal Research Committee, São Paulo State University (São José dos Campos, SP, Brazil) approved the protocol for all the experimental procedures performed.

Thirty-six adult male Wistar rats (4 months-old) weighing an average of $460 \mathrm{~g}$ were randomized into four groups ( 9 rats per group), as follows: Test group
A (low) - rats were fed an ethanol-containing liquid diet with ethanol representing $22 \%$ of total caloric value; Control group A - rats were fed a pair-fed control diet (ethanol replaced by isocaloric amounts of carbohydrate); Test group B (high) - rats were fed an ethanol-containing liquid diet with ethanol representing $36 \%$ of total caloric value; and Control group B - rats were fed a pair-fed control diet (ethanol replaced by isocaloric amounts of carbohydrate).

\section{Experimental procedures}

In Test group A, rats received a $10 \%$ ethanol solution (v/v) (Ecibra, CETUS, Santo Amaro, SP, Brazil) and, in Test group B, rats received a $20 \%$ ethanol solution $(\mathrm{v} / \mathrm{v})$, in addition to standard rat chow (Guabi Nutrilador, Mogiana Alimentos, Campinas, SP, Brazil), both provided ad libitum.

The mean quantities of rat chow and ethanol solution consumed were calculated daily and one day after ethanol administration. The control rats were fed an equal amount of rat chow as that consumed by rats in the alcohol group and an equal volume of liquid diet, with the ethanol replaced by isocaloric amounts of carbohydrate.

At the end of the experimental period, the mean quantity of ethanol consumed represented $22 \%$ of the total dietary energy intake per day in Test group $\mathrm{A}$ and $36 \%$ of the total dietary energy intake per day in Test group B.

Prior to the experimental period, the rats comprising Test group A and Test group B were subjected to an adaptation period in which the ethanol concentration was increased until it reached experimental concentrations. A solution containing 5\% ethanol was administered to ethanol Test group A for seven days, and ethanol Test group B received $5 \%$ ethanol for seven days and then $10 \%$ ethanol for another seven days.

After the adaptation period, general anesthesia was induced by intramuscular administration of a $2 \%$ xylazine hydrochloride solution $(13 \mathrm{mg} / \mathrm{kg})$ (Rompum-Bayer, São Paulo, SP, Brazil) and $33 \mathrm{mg} /$ $\mathrm{kg}$ of ketamine (Francotar-Virbac, Roseira, SP, Brazil). To induce alveolar bone loss, cotton ligatures were placed around the cervix of the right up- 
per second molar, while the contralateral teeth remained unligated to serve as controls. The ligature was knotted on the buccal side of the tooth.

After eight weeks, the rats were sacrificed by decapitation and the maxillary bones were fixed in $10 \%$ neutral formalin for $48 \mathrm{~h}$.

\section{Morphometric analysis}

The maxillae were defleshed and stained with an aqueous methylene blue solution $(1 \%)$ in order to differentiate bone from teeth.

Alveolar bone loss was evaluated morphometrically by measuring the distance between the cementoenamel junction (CEJ) and the alveolar bone crest $(\mathrm{ABC})$ at two buccal and two palatal sites in each maxilla. Three measurements were made along the long axis of the roots of the upper second molar on each side using the image analysis system Image Tool v.3.0 (UTHSCSA, San Antonio, TX, USA). The mean of these measurements was used as the measurement of alveolar bone loss on the buccal and palatal sides and per tooth. All measurements were made blind to the group to which the rat pertained.

In order to obtain sufficient reproducibility of the molar alignment on the image, the teeth should not overlap each other interproximally, and the buccal cusp tip of each molar should be superimposed on the corresponding lingual cusp tip.

\section{Statistical analysis}

The independent sample $t$-test was used to compare the differences between the diets consumed in the Test and Control groups.

The paired $t$-test was used to compare weight between baseline and final rat body weight in all groups, while the independent sample $t$-test was used to compare variations in weight between the Test and Control groups for low and high caloric values.

For morphometric analysis, the data were expressed as mean and standard deviation $(\mathrm{mm})$ and the independent sample $t$-test was used to determine significant differences in alveolar bone loss between the treatment groups (Test and Control for low and high caloric values) for ligated and unligated rats, separately. The paired $t$-test was used to compare alveolar bone loss between ligated and unligated teeth for the Test and Control groups.

Statistical significance for all differences was established at $5 \%(\mathrm{p}<0.05)$.

\section{Results Diet and weight analysis}

Diet analysis showed no significant differences in diet consumption $(p>0.05)$ between the Test and Control groups for low (Table 1) or high (Table 2) caloric values, considering the total number of calories consumed ( $\mathrm{kcal} / \mathrm{day})$, calories derived from protein, calories derived from alcohol or carbohydrate
Table 1 - Mean and standard deviation of diet analysis values (kcal/day) for the test and control groups associated with low caloric values.

\begin{tabular}{l|c|c}
\hline \multicolumn{1}{c|}{ Diet } & Test A (Ethanol Low) & Control A (isocaloric) \\
\hline Total calories consumed & $126.34 \pm 10.37$ & $125.58 \pm 10.18$ \\
\hline Calories derived from protein & $99.14 \pm 10.13$ & $98.69 \pm 9.92$ \\
\hline Calories derived from alcohol or carbohydrate & $27.20 \pm 1.08$ & $26.88 \pm 1.08$ \\
\hline \% calories from liquid diet & $21.72 \pm 1.83$ & $21.54 \pm 1.81$ \\
\hline$\%$ calories from solid diet & $78.28 \pm 1.83$ & $78.46 \pm 1.81$ \\
\hline
\end{tabular}

Table 2 - Mean and standard deviation of diet analysis values (kcal/day) for the test and control groups associated with high caloric values.

\begin{tabular}{l|c|c}
\hline \multicolumn{1}{c|}{ Diet } & Test B (Ethanol high) & Control B (isocaloric) \\
\hline Total calories consumed & $133.58 \pm 14.92$ & $133.54 \pm 14.87$ \\
\hline Calories derived from protein & $85.14 \pm 12.81$ & $85.14 \pm 12.81$ \\
\hline Calories derived from alcohol or carbohydrate & $48.44 \pm 4.12$ & $48.40 \pm 4.11$ \\
\hline$\%$ calories from liquid diet & $36.55 \pm 3.12$ & $36.47 \pm 3.23$ \\
\hline$\%$ calories from solid diet & $63.45 \pm 3.12$ & $63.53 \pm 3.23$ \\
\hline
\end{tabular}


and the percentage of calories of the liquid and solid diets.

Diet analysis showed that ethanol represented $21.72 \%( \pm 1.83)$ of the total dietary energy intake in Test group A and no significant difference $(p>0.05)$ was detected when compared to the control. In Test group B, ethanol represented $36.55 \%( \pm 3.12)$ of the total dietary energy intake and no significant difference $(p>0.05)$ was detected when compared to the control.

The systemic effect of alcohol consumption observed by analysis of rat body weight showed that Test group A ( $\mathrm{p}=0.007)$ and Test group B (0.0257) gained weight during the experimental period. Weight gain was also observed in Control group $\mathrm{A}$ $(\mathrm{p}=0.0104)$ and Control group $\mathrm{B}(\mathrm{p}=0.0000)$.

Analysis of rat body weight showed that weight gain was greater $(\mathrm{p}=0.0436)$ in the ethanol group than in the carbohydrate group associated with a diet of low caloric value (groups A). However, analysis of rat body weight associated with a diet of high caloric value (groups B) showed that weight gain was greater $(\mathrm{p}=0.0001)$ in the carbohydrate group than in the ethanol group (Table 3).

\section{Morphometric analysis}

Morphometric analysis showed that cotton ligatures placed around the teeth induced alveolar bone loss, which was confirmed by the greater bone loss $(\mathrm{p}<0.05)$ observed in ligated teeth compared to unligated teeth.

In unligated teeth associated with low caloric diet, intergroup analysis showed no significant differences in alveolar bone loss between Test group A and Control group A rats regarding the whole tooth $(\mathrm{p}=0.4160)$, buccal side $(\mathrm{p}=0.2796)$ and palatal side $(\mathrm{p}=0.4270)$ (Graph 1). However, morphometric analysis revealed a significantly greater bone loss in ligated teeth in rats that received $22 \%$ of caloric value of ethanol regarding the whole tooth $(\mathrm{p}=0.0230)$, buccal side $(\mathrm{p}=0.0440)$ and palatal side $(\mathrm{p}=0.0431)($ Graph 2$)$.

No significant intergroup differences were observed in alveolar bone loss between unligated teeth

Table 3 - Mean and standard deviation of weight analysis values (g) for the test and control groups associated with low and high caloric values.

\begin{tabular}{c|c|c|c}
\hline Groups & Baseline weight & Final weight & Variation \\
\hline Test A (Ethanol Low) & $450 \pm 15$ & $478 \pm 26.5^{*}$ & $(+) 30 \pm 17^{\circ}$ \\
\hline Control A (isocaloric) & $477 \pm 38$ & $492 \pm 34^{*}$ & $(+) 15 \pm 16$ \\
\hline Test B (Ethanol High) & $471 \pm 34.5$ & $483 \pm 28.5^{*}$ & $(+) 12 \pm 16^{\text {b }}$ \\
\hline Control B (isocaloric) & $433 \pm 35$ & $479 \pm 31^{*}$ & $(+) 46 \pm 9$ \\
\hline
\end{tabular}

${ }^{*} p<0.05$, baseline compared with final value (paired $t+$ test). ${ }^{a} p<0.05$, compared with the Control A group (independent $t$ test). ${ }^{b} p<0.05$, compared with the Control B group (independent $t$ test).

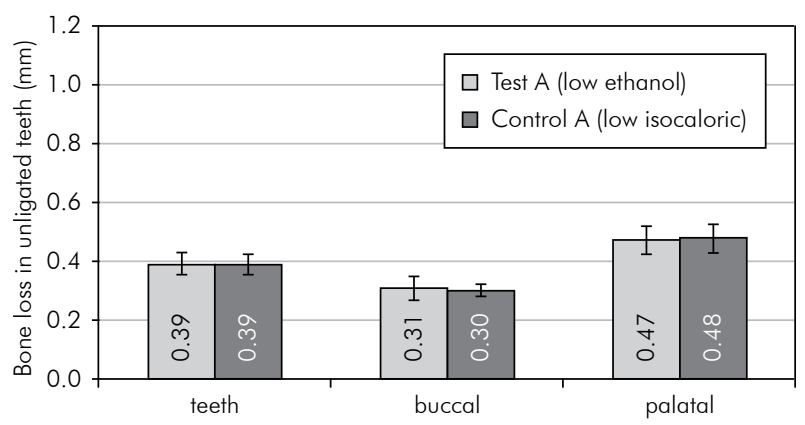

Graph 1 - Mean and standard deviation of alveolar bone loss $(\mathrm{mm})$ in unligated teeth associated with low caloric valves of ethanol and carbohydrate. *Statistically significant (ANOVA and Tukey test; $p<0.05$ ).

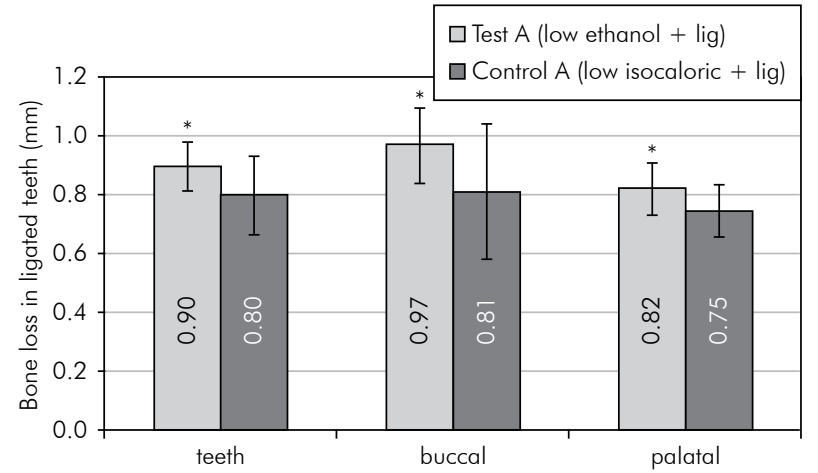

Graph 2 - Mean and standard deviation of alveolar bone loss $(\mathrm{mm})$ in ligated teeth associated with low caloric values of ethanol and carbohydrate. *Statistically significant (ANOVA and Tukey test; $p<0.05)$. 
associated with high caloric diet. The analysis compared means between Test group B and Control group B regarding the whole tooth $(\mathrm{p}=0.5195)$, buccal side $(\mathrm{p}=0.7383)$ and palatal side $(\mathrm{p}=0.6721)$ (Graph 3). In ligated teeth, analysis revealed no statistic significance in periodontal bone destruction between these groups regarding the whole tooth $(\mathrm{p}=0.2636)$, buccal side $(\mathrm{p}=0.3450)$ and palatal side $(\mathrm{p}=0.3289)($ Graph 4).

\section{Discussion}

Evidence exists that persistent alcohol abuse affects periodontal disease severity $y^{6,7,16,18}$ in patients. However, in some studies in humans this relationship has not been verified. ${ }^{19,20}$

An important study involving 13,198 individuals determined a moderate but consistent dose-dependent relationship between alcohol consumption and increased periodontal disease severity, represented by clinical attachment loss. ${ }^{7}$ Another study showed that persistent alcohol abuse, as determined by the presence of blood levels of a liver enzyme indicator of alcohol consumption, affects the severity of periodontal disease and established a positive correlation with loss of periodontal attachment. ${ }^{18}$

The Hisayama study ${ }^{20}$ did not determine a significant relation between drinking and clinical attachment loss, which may be due to the small sample size in this work and, more specifically, to the low number of alcohol consumers. Another study ${ }^{19}$ in adults found no significant effects of alcohol consumption

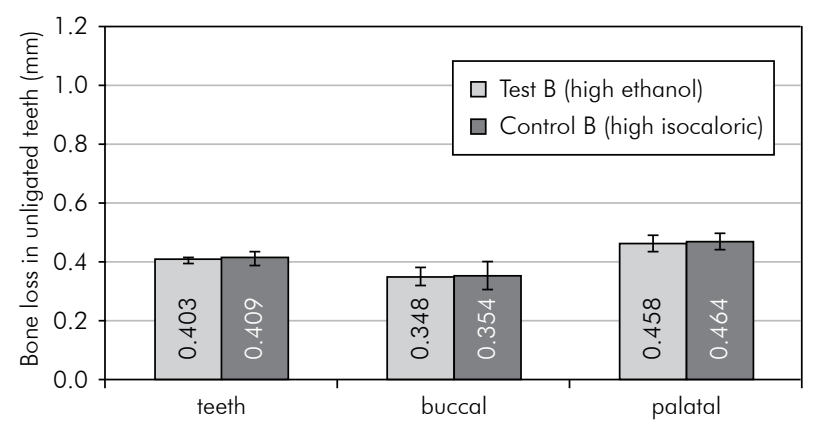

Graph 3 - Mean and standard deviation of alveolar bone loss $(\mathrm{mm})$ in unligated teeth associated with high caloric values of ethanol and carbohydrate. *Statistically significant (ANOVA and Tukey test; $\mathrm{p}<0.05$ ). on periodontal disease severity; however, drinkers were defined as individuals who consumed any type of alcoholic beverage and at least 12 alcoholic beverages in a one-year period. The authors used information regarding quantities per period that were much lower than those used in studies that found a significant interaction between alcoholic drinks consumed per week and periodontal disease. ${ }^{6,7}$

Animal models have been used to investigate the influence of risk indicators/factors on the progression of periodontitis, ${ }^{9-13}$ because the structure of rat periodontal tissue is very similar to that of humans. ${ }^{21}$ The association between alcohol consumption and periodontal disease has been the subject of recent analysis in this animal model. ${ }^{10-12}$

The experimental period of alcohol consumption used was based on previous studies involving rats that showed the negative effects of ethanol on bone metabolism over eight weeks. ${ }^{22,23}$ This same experimental period was used in the present study and others ${ }^{10-12}$ that evaluated the influence of ethanol consumption on periodontal disease in rats.

The morphometric method in rats was used because it is considered a reproducible method, it has the ability to discriminate between experimental groups $^{24,25}$ and the measurements obtained with it are not significantly different from the histological measurements of alveolar bone level in ligatured rats. $^{26}$

In the present study, the ligature-induced periodontitis lasted for 56 days because it was associat-

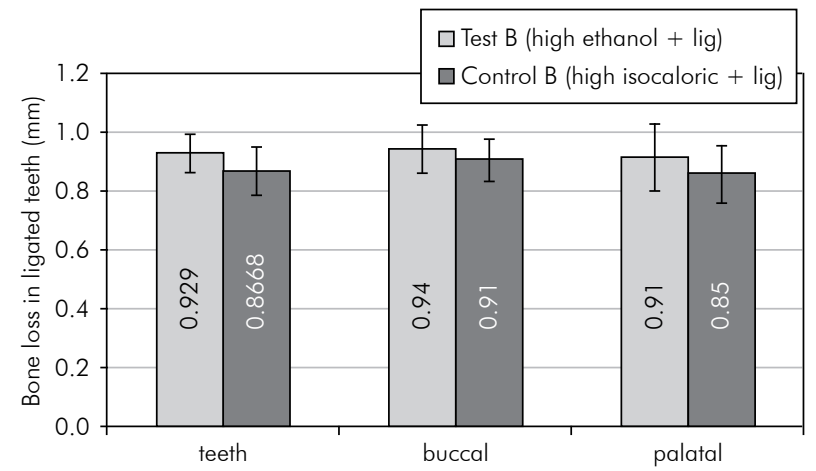

Graph 4 - Mean and standard deviation of alveolar bone loss $(\mathrm{mm})$ in ligated teeth associated with high caloric values of ethanol and carbohydrate. *Statistically significant (ANOVA and Tukey test; $\mathrm{p}<0.05$ ). 
ed with the total experimental period of ethanol administration. The same period was used to evaluate the influence of alcohol consumption on periodontal support in experimental periodontitis in rats. ${ }^{11}$

Among alcoholics, ethanol consumption represents a high percentage of the total dietary energy intake. As a consequence, alcohol displaces many normal dietary nutrients resulting in primary malnutrition. Moreover, secondary malnutrition may result from maldigestion or malabsorption caused by gastrointestinal complications. ${ }^{27}$

The reduction in human body weight during chronic alcohol consumption is associated with the fact that part of the daily diet calorie intake is provided by the alcoholic beverage ${ }^{27}$ however, this impact on weight is rarely observed in rats. ${ }^{28}$ In the present study, the systemic effect of alcohol consumption observed by analysis of rat body weight showed that groups that consumed ethanol or carbohydrates gained weight. Similarly, Irie et al. ${ }^{12}$, (2008) showed a weight gain in ethanol and isocaloric groups during the experimental period.

In this study, analysis of the results indicated that chronic ethanol feeding alone may not be capable of causing bone loss in rats associated with low $(22 \%)$ or high $(36 \%)$ caloric values. In contrast, Irie et al. ${ }^{12}$, (2008) showed that the distance between the cementoenamel junction and the alveolar bone crest was greater in the ethanol group $36 \%$ calories derived from ethanol) than in the respective control group.

In the presence of experimental periodontitis,

\section{References}

1. Kinane DF. Causation and pathogenesis of periodontal disease. Periodontol 2000. 2001;25:8-20.

2. Page RC, Offenbacher S, Schroeder HE, Seymour GJ, Kornman KS. Advances in the pathogenesis of periodontitis: summary of developments, clinical implications and future directions. Periodontol 2000. 1997;14:216-48.

3. Genco RJ. Current view of risk factors for periodontal diseases. J Periodontol. 1996;67(10):1041-9.

4. Nunn ME. Understanding the etiology of periodontitis: an overview of periodontal risk factors. Periodontol 2000. 2003;32:11-23.

5. Stanford TW, Rees TD. Acquired immune suppression and other risk factors/indicators for periodontal disease progression. Periodontol 2000. 2003;32:118-35. the effects of alcohol on alveolar bone loss observed in this study were dependent on the different caloric values of ethanol intake. Ethanol representing low caloric values ( $22 \%$ of total caloric value) aggravated the bone loss in ligature-induced periodontitis. When ethanol represents high caloric values $(36 \%$ of total caloric value) in the diet it may also present an indirect effect on periodontal tissue, affecting ligature-induced bone resorption, because primary and secondary malnutrition can develop that directly affects the pathogenesis of periodontitis.

In the presence of experimental periodontitis, Irie et al. ${ }^{12}$ (2008) showed that a high dose of ethanol itself ( $36 \%$ of total calories in the diet) was not capable of affecting ligature-induced bone resorption, or apical migration of junctional epithelium. However, a higher density of polymorphonuclear leukocytes was observed, increasing the severity of periodontal inflammation in the ligature model of male rats.

The results of this study suggest that ethanol may affect alveolar bone level differently in the presence or absence of experimental periodontitis and association with low or high caloric values of ethanol intake.

\section{Conclusion}

In conclusion, this study demonstrated that in male rats, ethanol itself increased ligature-induced bone loss when representing a low value in the total calorie intake.
6. Tezal M, Grossi SG, Ho AW, Genco RJ. The effect of alcohol consumption on periodontal disease. J Periodontol. 2001;72(2):183-9.

7. Tezal M, Grossi SG, Ho AW, Genco RJ. Alcohol consumption and periodontal disease. The Third National Health and Nutrition Examination Survey. J Clin Periodontol. 2004;31(7):484-8.

8. Weinberg MA, Bral M. Laboratory animal models in periodontology. J Clin Periodontol. 1999;26(6):335-40.

9. Bosco AF, Bonfante S, Almeida JM, Luize DS, Nagata MJH, Garcia VG. A Histologic and Histometric assessment of the influence of nicotine on alveolar bone loss in rats. J Periodontol. 2007;78(3):527-32. 
10. Souza DM. Efeito do consumo de álcool na periodontite induzida experimentalmente em ratos [Tese de Doutorado]. Faculdade de Odontologia de São José dos Campos da UNESP; 2006.

11. Souza DM, Ricardo LH, Prado MA, Prado FA, Rocha RF. The effect of alcohol consumption on periodontal bone support in experimental periodontitis in rats. J Appl Oral Sci. 2006;14(6):443-7.

12. Irie K, Tomofuji T, Tamaki N, Sanbe T, Eruni D, Azuma T et al. Effects of ethanol consumption on periodontal inflammation in rats. J Dent Res. 2008;87(5):456-60.

13. Peruzzo DC, Benatti BB, Antunes IB, Andersen ML, Sallum EA, Casati MZ et al. Chronic Stress may modulate periodontal disease: a study in rats. J Periodontol. 2008;79(4):697-704.

14. Hornecker E, Muuss T, Ehrenreich H, Mausberg RF. A pilot study on the oral conditions of severely alcohol addicted persons. J Contemp Dent Pract. 2003;4(2):51-9.

15. Novacek G, Plachetzky V, Potzi R, Lentner S, Slaviccek R, Gangl A et al. Dental and periodontal disease in patients with cirrhosis: role of etiology of liver disease. J Hepatol. 1995;22(5):576-82.

16. Pitiphat W, Merchant AT, Rimm EB, Joshipura KJ. Alcohol consumption increases periodontitis risk. J Dent Res. 2003;82(7):509-13.

17. Nishida N, Tanaka M, Hayashi N, Nagata H, Takeshita T, Nakayama $\mathrm{K}$ et al. Association of $\mathrm{ALDH}_{2}$ genotypes and alcohol consumption with periodontitis. J Dent Res. 2004;83(2):1615.

18. Khocht A, Janal M, Schleifer S, Keller S. The influence of gingival margin recession on loss of clinical attachment in alcohol-dependent patients without medical disorders. J Periodontol. 2003;74(4):485-93.

19. Torrungruang K, Tamsailom S, Rojanasomsith K, Sutdhibhisal $\mathrm{S}$, Nisapakultorn K, Vanichjakvong $\mathrm{O}$ et al. Risk indicators of disease in older Thai adults. J Periodontol. 2005;76(4):55865.

20. Shimazaki Y, Saito T, Kiyohara Y, Kato I, Kubo M, Iida M et al. Relationship between drinking and periodontitis: the Hisayama study. J Periodontol. 2005;76(9):1534-41.

21. Page RC, Schroeder HE. Periodontitis in man and other animals: a comparative review. New York: Karger; 1982.

22. Hogan HA, Sampson HW, Cashier E, Ledoux N. Alcohol consumption by young actively growing rats: a study of cortical bone histomorphometry and mechanical properties. Alcohol Clin Exp Res. 1997;21(5):809-16.

23. Hogan HA, Argueta F, Moe L, Nguyen LP, Sampson HW. Adult-onset alcohol consumption induces osteopenia in female rats. Alcohol Clin Exp Res. 2001;25(5):746-54.

24. Klausen B, Evans RT, Sfintescu C. Two complementary methods of assessing periodontal bone level. Scand J Dent Res. 1989;97(6):494-9.

25. Souza DM, Rosa LP, Ricardo LH, Moraes L C, Rocha RF. Avaliação óssea alveolar de Rattus norvegicus por meio dos métodos radiográfico e morfométrico. Cienc Odontol Bras. 2005;8(4):77-84.

26. Fernandes MI, Gaio EJ, Oppermann RV, Rados PV, Rösing CK. Comparison of histometric and morphometric analyses of bone height in ligature-induced periodontitis in rats. Braz Oral Res. 2007;21(3):216-21.

27. Lieber CS. Relationships between nutrition, alcohol use, and liver disease. Alcohol Res Health. 2003;27(3):220-31.

28. Reed AH, McCarty HL, Evans GL, Turner RT, Westerlird KC. The effects of chronic alcohol consumption and exercise on the skeleton of adult male rats. Alcohol Clin Exp Res. 2002;26(8):1269-74. 